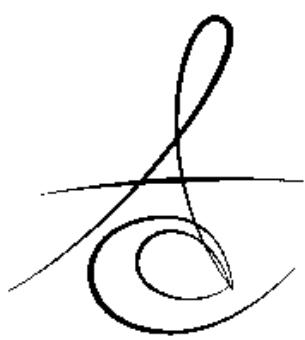

\title{
AŞIRI DİŞ AŞINMASI OLAN BİR HASTANIN TAM ARK RESTORASYONU VE ISIRMA KUVVETİNİN DEĞERLENDİRİLMESİ: VAKA RAPORU\#
}

\section{FULL MOUTH REHABILITATION OF A PATIENT WITH SEVERELY WORN DENTITION AND EVALUATION OF BITE FORCE: A CASE REPORT ${ }^{*}$}

\author{
Dr. Duygu KARAKIŞ*
}

Prof. Dr. Arife DOĞAN*

Makale Kodu/Article code: 1500

Makale Gönderilme tarihi: 26.01 .2014

Kabul Tarihi: 19.02 .2014

\section{ÖZET}

Ciddi diş aşınmasının fonksiyonel ve estetik olarak rehabilitasyonu restoratif alan için yeterli yer olmamasından dolayı bazı problemlere neden olmaktadır. Sunulan vakada 60 yaşındaki erkek hastada yaygın diş aşınmaları, ön çapraz kapanış ve çiğneme fonksiyonunda sorunlar mevcuttu. Detaylı muayenenin ardından oklüzal vertikal boyutun (OVB) arka dişlerde $2 \mathrm{~mm}$ artırımasına karar verildi. Tedavi öncesinde sefalometrik film alınmış ve maksimum ısırma kuvveti 20 kg/kuvvet olarak ölçüldü. Ardından hastanın artırılmış OVB'ye adaptasyonu için sabit geçici restorasyonlar hastaya 1 ay kullandırıldı. $\mathrm{Bu}$ yükseltilmiş OVB'de geçici restorasyonlar ile ikinci bir sefalometrik film alındı. Bir aylık kontrol sonunda hastada herhangi bir kas ağrısı ve eklem rahatsızlığına dair şikâyetin olmaması nedeniyle tam ark restorasyonu tamamlandı. Restorasyonun daimi simantasyonunundan bir hafta sonra yapılan kontrolde hasta rahat bir şekilde çiğneme yapabildiğini ifade etti. Kontrolde ısırma kuvveti kaydı tekrar alındı ve hastanın maksimum ısırma kuvveti 32 kg/kuvvet olarak ölçülmüştür.

Anahtar kelimeler: Diş aşınması, vertikal boyut, Isırma kuvveti

\section{ABSTRACT}

Aim: The Cleft Lip and Palate (CLP) is variation of a Aesthetic and functional restoration of the severely worn dentiton leads to some challenges due to the insufficient restorative space. In the present case report, 60 years-old male patient had generalized tooth wear, anterior cross-bite, aesthetic problems and impaired masticatory function. After the detailed examination, $2 \mathrm{~mm}$ increase of occlusal vertical dimension (OVD) in posterior teeth has been decided. Before treatment, cephalometric radiographs were taken and maximum bite force was measured as 20 $\mathrm{kg} /$ kuvvet. Then, for adaptation of patient to the increased OVD, patient used the fixed provisional restoration for 1 month. A second cephalometric radiograph was taken with the provisional restoration at increased OVD. After 1 month, patient did not report any muscle pain or joint discomfort and thus permanent full mouth restoration was completed. One week later of permanent cementation of restorations, patient reported satisfactory masticatory function and at this appointment the bite force was measured as $32 \mathrm{~kg} / \mathrm{kuvvet}$.

Key words: Tooth wear, vertical dimension, bite force

\section{GİRİŞ}

Diş aşınması dişlerde çürük, travma ve gelişimsel bozukluk olmadan görülen diş dokusu kaybı olarak tanımlanmaktadır. ${ }^{1}$ Diş aşınması nedenlerine göre atrisyon, erozyon, abrazyon ve abfracsiyon olarak sınıfllandırılmakta ve çok faktörlü etiyoloji sonucu oluştuğu düşünülmektedir. ${ }^{2,3} \mathrm{Bu}$ nedenle, diş aşınması olan hastalarda aşınmaya neden olan faktörün belirlenerek her hastaya özel bir tedavi planı uygulanmalıdır. ${ }^{4}$

Diş aşınması varlığında, dişlerde hassasiyet, ağrı ve çiğneme fonksiyonunda sorunların yanı sıra estetik problemler görülür. ${ }^{5}$ Genel olarak, aşınmış

*Protetik Diş Tedavisi Anabilim Dalı, Gazi Üniversitesi Diş Hekimliği Fakültesi,

\#Bu yayın, uluslararası 37. European Prosthodontic Association (EPA) kongresinde poster olarak sunulmuştur. (21-24 Ağustos 2013, Turku, Finlandiya) 
dişlere sahip bireylerde oklüzal vertikal boyutta (OVB) düşüş olduğu görüşüne $\operatorname{karşın}^{5,6}$ bazı yazarlar diş aşınmasının OVB'de kayıp oluşturacağı görüşünü reddetmekte ve aşınmış dişler sonucu görülen dikey boyut kaybının devamlı diş erüpsiyonu veya alveoler gelişim ile tolere edilebildiğini bildirmektedirler. ${ }^{2,7-9}$ Ciddi aşınma alanlarında alveoler proseslerin oldukça genişlemesi, orijinal OVB'u tolere edici adaptasyonların olduğunun göstergesidir. ${ }^{10} \mathrm{Ancak}$, diş aşınmasının bu tolere edici mekanizmaları aştığı durumlarda OVB kaybı görülür; böyle durumlarda diş aşınması yavaş ilerler ve karşıt çenedeki dişlerin erüpsiyonu restorasyon için gerekli mesafeyi ortadan kaldırır. ${ }^{11}$ Dolayısıyla, aşınmış dişlerin estetik ve fonksiyon amaçı restorasyonu sırasında restoratif tedavi için yer sağlanması OVB'nin arttırımasını gerektirebilir.

Hastanın arttırımış dikey boyuta adaptasyonu, genellikle geçici protezler (doğrudan bağlanan kompozit rezin veya geçici sabit restorasyonlar) veya tanısal splintler yardımı ile kontrol edilebilir. ${ }^{12}$ Artırılan OVB'nin olası adaptasyon mekanizması, çiğneme kaslarının boyunda artı̧̧ ve relaksasyon, dentoalveoler maturasyon veya bu iki mekanizmanın kombinasyonuna bağı olabilir. Bulgular, dentoalveoler maturasyondan ziyade kas relaksasyonu ve kas boyu değişikliklerinin birincil adaptasyon mekanizması olduğunu göstermektedir. ${ }^{13}$

Aşınmış dişlerin restorasyonunda OVB'nin artırımasının çiğneme sistemi komponentleri ve uzun dönemli oklüzal stabilite üzerine etkisinin ve konuşma değişikliğinin önceden belirlenmesi için geçiş tedavisinin gerekli olduğu bildirilmiştir. ${ }^{14}$

Bu olgu sunumunda, aşınmış dişler ve ön çapraz kapanışa sahip bir hastada, ısırma kuvveti kayıtları ve sefalometrik filmleri alınarak kontrollü bir OVB yükseltilmesi ardından alt ve üst çenenin tam ark restorasyonunun yapımı sunulmaktadır.

\section{OLGU SUNUMU}

60 yaşındaki erkek hasta dişlerinde genel hassasiyet, çiğneme rahatsızlığı ve estetik şikayetleri nedeniyle başvurdu. Hastanın ağız içi muayenesi ile 33 ve 43 numaralı dişleri arasında köprü restorasyonu bulunduğu ve hastanın ön çapraz kapanışı olduğu görüldü. Üst kesiciler, üst sol kanin, premolar ve molar dişlerin servikal üçlülerinde abfraksiyon şeklinde aşınma ve diğer dişlerin de oklüzalinde yaygın atrizyona bağlı aşınmalar görüldü (Resim 1). Bazı dişlerde oklüzal yüzeylerde dentinin açığa çıktığı ve pulpa boynuzuna kadar aşınmanın ilerlemiş olduğu tespit edildi. Hastanın temporomandibular eklem muayenesinde eklem sesi, palpasyonda eklemde ağrı, hareket kısıtlılı̆ı, çiğneme kasları ile baş ve boyun kaslarında ağıı tespit edilmedi. Detaylı ağız içi ve ağız dışı muayeneden sonra, hastanın hidrokolloid ölçü maddesi (Hydrocolor 5, Zhermack, Zhermack SpA., Badia Polesine, İtalya) ile ölçüsü alınarak tanısal modeller elde edildi. Yüz arkı kaydı (UTS Face-bow, Ivoclar, Avusturya) ve interoklüzal kayıtlar alınarak modeller yarı-ayarlanabilir artikülatöre (Stratos 300, Ivoclar-Vivadent Inc. Avusturya) aktarıldı (Resim 2). Artikülatöre alınmış modeller üzerinde yapılan detaylı inceme sonucu, hastanın ön çapraz kapanışını düzeltmek amacıyla hastanın oklüzal dikey boyutunun alt ve üst arka dişlerde $2 \mathrm{~mm}$ arttırılmasına karar verildi ve artikülatörün insizal pini bu boyuta göre ayarlandı. Planlanan yeni dikey boyutta tanısal mumlama yapılarak hasta ile birlikte dişlerin pozisyon, kontur ve estetiği değerlendirildi (Resim 3). Hastanın tedavi öncesi sefalometrik filmi alındı (Kodak T Mate, EKC, Roachester NY, ABD) ve hastanın maksimum ısırma kuvveti gerinim ölçer dönüştürücü (Model VLPB, Load Cell Central, Monroeton, PA, ABD) ile ölçüldü ve bu değer $20 \mathrm{~kg} /$ kuvvet olarak belirlendi. Alt ve üst dişlerin preparasyonu sırasında belirlenen dikey boyutun korunmasında rehberlik sağlaması ve diş kesim miktarını belirlemede yardımcı olması için, ısırma kaydı splinti yapıldı ve splint rehberliğinde alt ve üst tüm dişlerin preparasyonu tamamlandı. Daha sonra polivinilsiloksan ölçü materyali (Optosil Comfort/ Xantopren VL Plus, Heraeus Kulzer, Hanau, Almanya) ile esas ölçüler alınarak, geçici amaçla kullanılmak üzere tam-ark akrilik geçici restorasyonlar yapıldı. Bu yükseltilmiş dikey boyuttaki geçici restorasyonlar ile ikinci bir sefalometrik film alınarak yeni dikey boyuttaki kondil pozisyonunun doğruluğu ve yükseltilmiş OVB'nin iskeletsel yüz morfolojisi üzerindeki etkisi değerlendirildi (Resim 4). Sefalometrik analiz sonucu dikey boyut artışı ile beraber total ön yüz yüksekliği ve alt yüz yüksekliğinin $4 \mathrm{~mm}$ arttığı tespit edildi. Yükseltilmiş dikey boyuta hastanın adaptasyonunun gözlenmesi için bu restorasyonlar hastaya 1 ay süreyle kullandirıldı. Bir ve 3 haftalık kontrollerinde hastanın yeni dikey boyuta adaptasyonu ile hastanın estetik, fonksiyon ve fonasyonu değerlendirildi. Kontrollerde kas ve eklem muayenesi sonucunda herhangi bir kas ağrısı ve 
eklem rahatsızlığı gözlenmemesi üzerine hastanın alt ve üst tam ark restorasyonunun yapımı rutin klinik işlemler uygulanarak tam ark metal destekli-seramik restorasyonlar organik okluzyon ilkelerine uygun tamamlandı (Resim 5). Geçici simantasyonu takiben, bir hafta sonra çinko polikarboksilat siman (AdhesorCarbofine, Spofa-Dental, Almanya) ile daimi olarak yapıştııldı. Klinik kontrol randevusunda, hasta rahat bir şekilde çiğneme yapabildiğini ifade etti; bu seansta ısırma kuvveti kaydı tekrarlandı ve hastanın maksimum ısırma kuvveti 32 kg/kuvvet olarak ölçüldü. Hastanın1 yıl sonraki kontrollerinde herhangi bir sorun görülmedi.

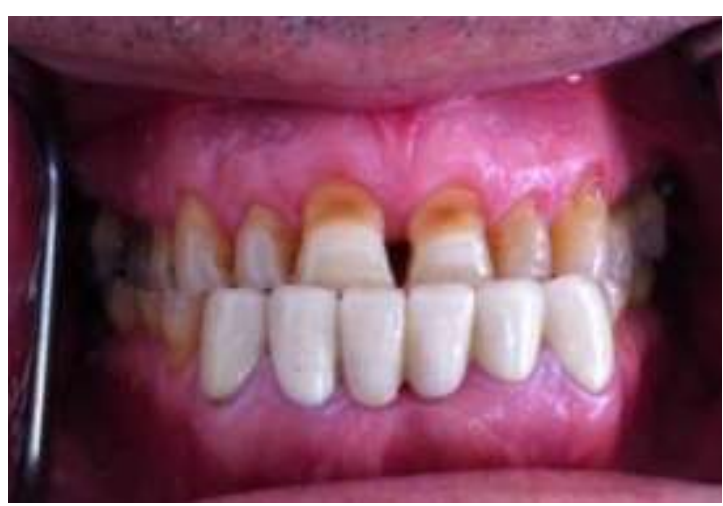

Resim 1.Ağız içi görünüm

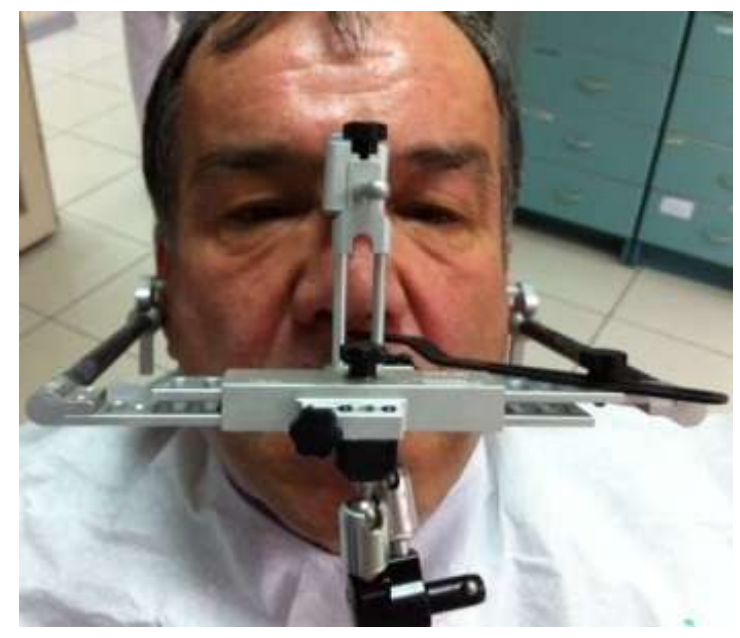

Resim 2. Facebow kaydı

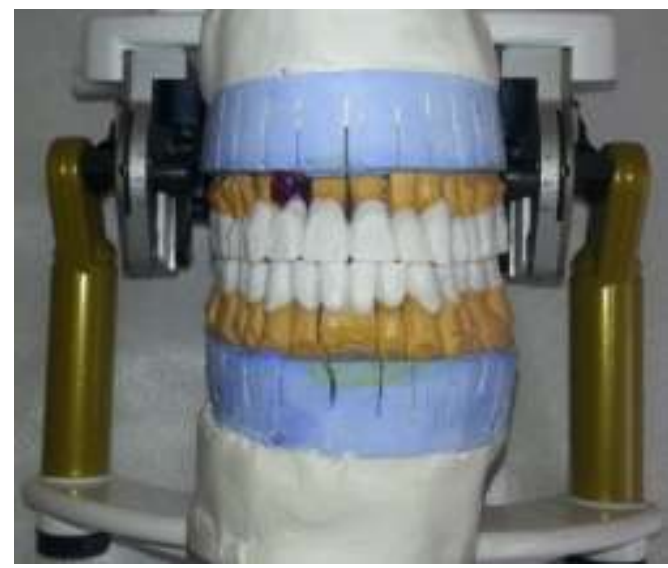

Resim 3. Tanısal mumlama

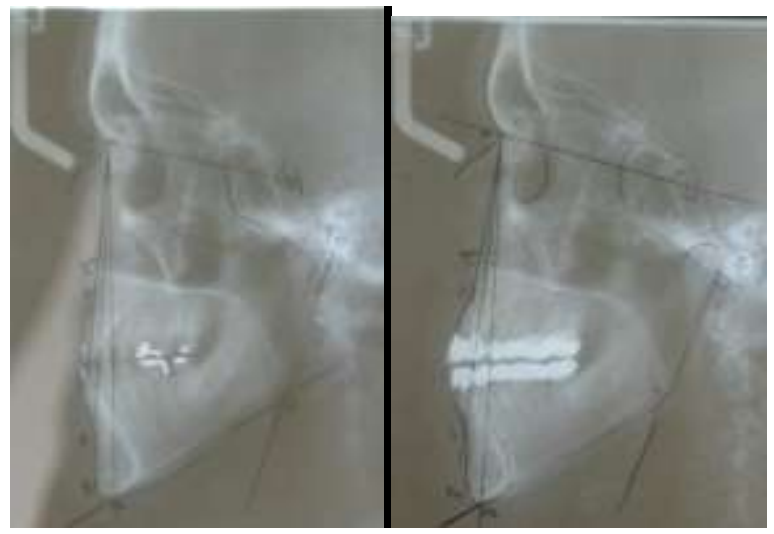

Resim 4. Dikey boyut yükseltme öncesi ve sonrası sefalometrik film

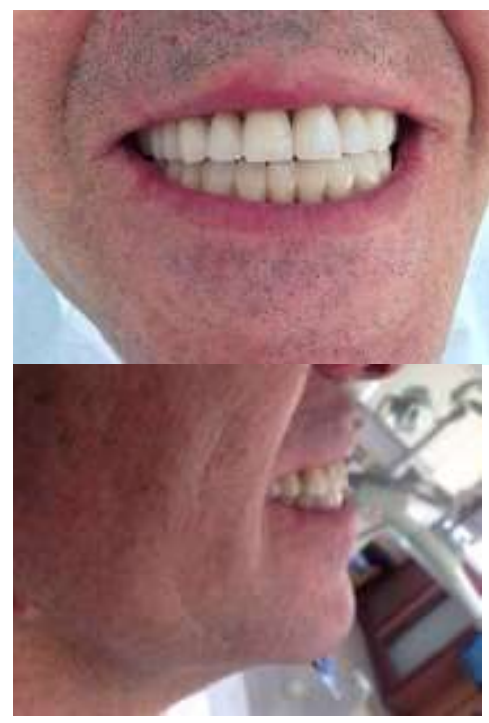

Resim 5. Tedavi sonu hastanın önden ve profilden görünümü 


\section{TARTIŞMA}

Atrizyon, fonksiyon ve parafonksiyon süresince kontakta olan diş yüzeylerinde aşınma olarak ifade edilirken, abfraksiyon, mekanik yükler sonucu dişlerin servikal bölgelerinde $\quad$-şeklindeki defektlerle karakterize diş dokusunun patolojik kaybı olarak tanımlanmaktadır. ${ }^{6,15}$ Önceki çalışmalarda oklüzal aşınma ve servikaldeki V-şeklindeki lezyonlar arasında bir korelasyon olduğu ve abfraksiyonun doğal dentisyondaki eksentrik kuvvetler sonucu oluştuğuna işaret edilmektedir. ${ }^{16,17}$ Lee ve Eakle, ${ }^{18}$ oklüzal ve lateral gezinmeler sırasında oluşan oklüzal temas noktalarından kaynaklanan koronal streslerin dişin servikal lezyonlarında önemli etiyolojik etken olduğunu bildirmişlerdir. Sunulan olguda dişlerde generalize diş aşınmalarına servikal üçlü abfraksiyonlarının eşlik ettiği gözlenmekte ve nedenin ideal olmayan okluzal yük dağılımı olduğu düşünülmektedir.

Aşınmış dişlerde OVB'nin artırıma miktarının belirlenmesine yönelik ilgili literatürde farklı görüşler mevcuttur. ${ }^{13,19,20}$ Bazı araştırıcılar, öncelikle istirahat dikey boyutunun değerlendirilmesi gereğine işaret etmişler ve interoklüzal rest aralığının $2 \mathrm{~mm}$ 'den fazla olduğu durumlarda OVB'nin arttırılabileceği bildirmişlerdir. ${ }^{19,20}$ Ancak buna karşın, klinik çalışmalarda interoklüzal rest aralığını geçecek şekilde OVB arttırıldığı vakalarda hastalarda patolojik reaksiyonlar ve adaptasyon sorunları görülmemiş ve bu nedenle interoklüzal rest_aralığının kriter olarak kullanılamayacağı anlaşılmıştır. ${ }^{13}$ Öte yandan, Harper ve ark. ları $^{21}$ okluzal vertikal boyutun artırılmasının iki önemli ilkenin korunması kapsamında dikkate alınmasını önermişlerdir. İlki, planlanan oklüzal dikey boyutun başlangıç noktasında kondilin sentrik ilişkide olması gerekliliğidir. İkincisi ise OVB artışının her bir hastanın nöromusküler uyum mekanizma sınırları içinde olması gerektiğidir. Benzer şekilde, Spear, ${ }^{22}$ eklem sistemi sağlıklı olduğu sürece ve kondil sentrik ilişki noktasından fonksiyonları yaptığı sürece hastanın birçok kabul edilebilir OVB'yi kullanabileceğini bildirmiştir. Bu görüşler ışığında, vakamıda yükseltilen OVB'de hastanın geçici restorasyonlarıyla sefalometrik filmleri alınarak, artmış OVB boyutta kondillin sentrik ilişki konumunda olup olmadığı kontrol edilmiş ve geçici restorasyonlar 1 ay süre ile kullandırılarak hastanın artan dikey boyuta adaptasyonu değerlendirilmiştir.
Hastaların artan dikey boyuta nöromusküler adaptasyonunun genellikle oklüzal splint veya geçici restorasyon (direk kompozit rezin uygulamaları veya geçici restorasyonlar) veya onlay protezler kullanımıyla yapılabileceği bildirilmektedir. ${ }^{11,12,23,24} \mathrm{Bu}$ yöntemler arasında, yapım ve uyumlamaları kolay olsa da, okluzal splintler, hareketli apareylerdir ve konuşmada sorun yaratabilirler. Aynı amaçla onley protezler sık kullanılmakla beraber, yüksek maliyet zor yapım işlemleri ve uyumlama güçlüğü ve konuşma sorunları gibi dezavantajlara sahiptir. ${ }^{20}$ Oysa geçici restorasyonlar hastanın diğer splint ve overlay protezlerden farklı olarak konuşma, estetik ve fonksiyonun birebir kontrolüne olanak sağlamakta ${ }^{13}$ ve gerekli düzenlemelerin hasta ağzında yapılması kolaylığı yönünden diğer yöntemlere göre avantaj sunmaktadırlar. Öte yandan, daimi tedavi planlamasına yönelik önceki çalışmalar, artırımış OVB'ye adaptasyonunun sabit protezlerle değerlendirilmesinin, hareketli protezlere göre hastalarda daha az semptom oluşturduğunu bildirmektedir. ${ }^{25,26} \mathrm{Bu}$ nedenle OVB artışının hareketli apareylerden ziyade sabit protezlerle yapılması gerektiği ve hareketli apareylerin OVB artışından ziyade hareketli apareye adapte olamamaktan kaynaklı sorunlar oluşturabileceği belirtilmektedir. ${ }^{13}$ Sabit protezler doğal diş morfolojisinin taklit etme olanağı sağlama, azalmış hacimlerinden dolayı konuşmada çatışma yaratmama ve genel olarak kullanımın daha kolay olması gibi avantajlara sahiptir. Ayrıca, hastanın şikâyetlerini azaltma ve tedaviyi kabülü kolaylaştırmada da tercih nedeni olabilir.

$\mathrm{Bu}$ tür vakalarda, yeni OVB tespitinde sefalometrik analizlerin yardımcı olarak kullanılabileceği bildirilmiştir. ${ }^{19,27}$ Sefalometrik analizle kondillerin mandibular fossalardaki konumlarına ek olarak, oklüzal plan, Spee eğrisi, ön diş pozisyonu, anterior rehberlik ve yüz morfolojisindeki değişimler de değerlendirilebilmektedir. ${ }^{19}$ Böyle bir analizle, oklüzyondaki alt yüz yüksekliğinin belirlenmesinin kas-iskelet sistemine en iyi uyumu sağlayacak OVB konusunda klinisyenlere bilgi sağlayabileceği bildirilmiştir. ${ }^{19}$ Sierpinska ${ }^{27}$ diş aşınması olan bireylerde oklüzal dikey boyut yükseltmesi sonucu yüzdeki birçok ölçümlerin bilinen referans değer aralığına ulaştığını göstermiştir. Hastamızın sefalometrik analizi sonucu dikey boyut artışı ile beraber total ön yüz yüksekliğinin ve alt yüz yüksekliğinin $4 \mathrm{~mm}$ arttığı tespit edilmiştir ve restorasyon 
sonrasında alt yüz yüksekliği diğer yüz ölçüm oranları ile uyumlu değere ulaşmıştır.

Ön çapraz kapanış varlığında estetik sorunlar ve anterior rehberliğin olmaması sonucu fonksiyon sorunları görülebilmektedir. ${ }^{13}$ Bu vakada OVB'nin arttırılmasıyla beraber estetik bir görünümle beraber overjet ve overbite tekrar oluşturularak anterior rehberlik sağlanmıştır. Hastamızda oklüzyon karşılıklı koruyuculu olarak oluşturularak, lateral kuvvetlerin çalışan taraftaki bütün dişlere dağılımı sağlanmıştır. Anterior rehberlik ile protrusif hareket sırasında arka dişlerin korunması amaçlanmıştır. Bu sayede dengeli bir oklüzyonla uygun bir kuvvet dağılımı sağlanacaktır ${ }^{13}$.

Isırma kuvveti ölçümünün çiğneme sisteminin bir göstergesi olduğu birçok çalışmada gösterilmiştir. $^{28,29}$ OVB yükseltilmesi yapılan hastamızın tedavi öncesi $20 \mathrm{~kg} /$ kuvvet olan ısırma kuvveti tedavi sonrası artarak $32 \mathrm{~kg} / \mathrm{kuvvet}$ olarak ölçülmüş ve hasta çiğneme fonksiyonun rahat bir şekilde yapabildiğini ifade etmiştir. Yapılan çalışmalarda, dikey boyut yükseltilmesini takiben çiğneme kaslarının aktivitelerinin arttığı bildirilmiştir. ${ }^{27,30,31}$ Hastanın ısırma kuvvetindeki bu artışın vertikal boyut artışına bağı kas fibrillerinin boylarındaki değişiklik sonucu oluştuğu düşünülmektedir. ${ }^{32}$ Hastamızda artan ısırma kuvveti ve artmış çiğneme fonksiyonu bulgularıyla uyumlu olarak, English ve ark.ları $^{33}$ ısırma kuvvetinin çiğneme aktivitesini etkilediğini bildirmişlerdir.

\section{KAYNAKLAR}

1. Hattab F, Yassin O. Etiology and diagnosis of tooth wear: a literature review and presentation of selected cases. Int J Prosthodont 2000;13:101-7.

2. Song MY, Park JM, Park EJ. Full mouth rehabilitation of the patient with severely worn dentition: a case report. J Adv Prosthodont 2010;2:106-10.

3. Abdullah A, Sherfudhin $H$, Omar $R$, Johansson A. Prevalence of occlusal tooth wear and its relationship to lateral and protrusive contact schemes in a young adult Indian population. Acta Odontol Scand 1994;52:191-7.

4. Verrett RG. Analyzing the etiology of an extremely worn dentition. J Prosthodont 2001;10:224-33.
5. Turner KA, Missirlian DM. Restoration of the extremely worn dentition. J Prosthet Dent 1984;52:467-74.

6. Bachhav VC, Aras MA. Altering occlusal vertical dimension in functional and esthetic rehabilitation of severely worn dentition. J Oral Health Res 2000;1:1-8.

7.Ramfjord SP, Blankenship JR. Increased occlusal vertical dimension in adult monkeys. J Prosthet Dent 1981;45:74-83.

8.Crothers A, Sandham A. Vertical height differences in subjects with severe dental wear. Euro J Orthod 1993;15:519-25.

9. Bloom DR, Padayachy JN. Increasing occlusal verticsl dimension- Why, when and how. Br Dent J 2006;200:251-6.

10. Dawson PE. Functional Occlusion: From TMJ to smile design. $1^{\text {st }}$ ed. Newyork: Elsevier Inc; 2008.p.430-52.

11. Moslehifard E, Nikzad S, Geraminpanah F, Mahboub F. Full mouth rehabilitation of a patient with severely worn dentition and uneven occlusal plane: A clinical report. J Prosthodont 2012;21:5664.

12. Hemmings KW, Howlett JA, Woodley NJ, Griffiths BM. Partial dentures for patients with advanced tooth wear. Dent Update 1995;22:52-9.

13. Abduo J, Lyons K. Clinical considerations for increasing occlusal vertical dimension: areview, Aust Dent J 2012;57:2-10.

14. Lerner J. A systematic approach to full-mouth reconstruction of the severely worn dentition. Pract Proced Aesthet Dent 2008;20:81-7.

15. Litonjua LA, Andreana S, Bush PJ, Tobias TS, Cohen RE. Noncarious cervical lesions and abfractions. J Am Dent Assoc 2003;134:845-50.

16.Grippo JO: Abfractions: A new classification of hard tissue lesions of teeth. J Esthet Dent 1991;3:14-9.

17. Lee WC, Eakle WS: Stress-induced cervical lesions: Review of advances in past 10 years. J Prosthet Dent 1996;75:487-94.

18. Lee WC, Eakle WS. Possible role of tensile stress in the etiology of cervical erosive lesions of teeth. ] Prosthet Dent 1984;52:374-80.

19. Orthlieb JD, Laurent M, Laplanch O. Cephalometric estimation of Vertical Dimension of Occlusion. J Oral Rehabil 2000;27:802-7. 
20. Prasad S, Kuracina J, Monaco EA. Altering occlusal vertical dimension provisionally with base metal onlays: A clinical report. J Prosthet Dent 2008;100:338-42.

21. Harper RP. Clinical indications for altering verticl dimension of occlusion. Quintessence Int 2000;31:275-82.

22. Spear FM. Approaches to vertical dimension. Advanced Esthetics and Interdisciplinary Dentistry 2006;2:2-12.

23. Ibbetson RJ, Setchell DJ. Treatment of the worn dentition. Dent Update 1989;16:305-7.

24. Öncül B, Kocabalkan E. Oklüzyon dikey boyutu ve yüz profilinin dişüstü hareketli protez ile restorasyonu: Bir olgu bildirimi. Atatürk Ünv.Diş Hek. Fak.Derg.2004;14:78-82.

25.Dahl BL, Krogstad. The effect of partial bite raising splint on the occlusal face height. An x-ray cephalometric study in human adults. Acta Odontol Scand 1982;40:17-24.

26.Dahl BL, Krogstad O. Long-term observations of an increased occlusal face height obtained by a combined orthodontic/prosthetic approach. J Oral Rehabil 1985;12:173-6.

27. Sierpinska T, Kuc J, Golebiewska M. Morphological and functional parameters in patients with tooth wear before and after treatment. Open Dent J 2013;7:55-61.

28. Koc D, Dogan A, Bek B. Bite force and influential factors on bite force measurements: A literature review. Eur J Dent. 2010;4:223-32.

29. Bakke M. Bite force and occlusion. Semin Orthod 2006;12:120-6.

30. Ferrario VF, Sforza C, Sartori M, Ciusa V. The mechanical advantage of the masseter muscle in subjects with different vertical and sagittal facial morphology. Clin Orthod Res 1999;2:162-70.

31. Kiliaridis $S$, Johansson A, Haraldson $T$, Omar $R$, Carlsson G. Craniofacial morphology, occlusal traits and bite force in persons with advanced occlusal tooth wear. Am J Orthod Dentofacial Orthop 1995;107:286-92.

32. Manns A, Miralles R, Palazzi C. EMG, bite force, and elongation of the masseter muscle under isometric voluntary contractions and variations of vertical dimension. J Prosthet Dent 1979;42:67482.
33. English JD, Buschang PH, Throckmorton GS. Does malocclusion affect masticatory performance? Angle Orthod 2002;72:21-7.

\author{
Yazışma Adresi \\ Duygu KARAKIŞ \\ Gazi Üniversitesi \\ Diş Hekimliği Fakültesi \\ Protetik Diş Tedavisi Anabilim Dalı \\ 06510, Emek, Ankara, Türkiye \\ Mail : dtduygukc@hotmail.com \\ duygukoc@gazi.edu.tr
}

